\title{
16S rDNA Pyrosequencing Analysis of Bacterial Community in Heavy Metals Polluted Soils
}

\author{
Marcin Golębiewski • Edyta Deja-Sikora • \\ Marcin Cichosz • Andrzej Tretyn • Borys Wróbel
}

Received: 5 March 2013 / Accepted: 4 December 2013 / Published online: 9 January 2014

(C) The Author(s) 2014. This article is published with open access at Springerlink.com

\begin{abstract}
Soil contamination with heavy metals is a widespread problem, especially prominent on grounds lying in the vicinity of mines, smelters, and other industrial facilities. Many such areas are located in Southern Poland; they are polluted mainly with $\mathrm{Pb}, \mathrm{Zn}, \mathrm{Cd}$, or $\mathrm{Cu}$, and locally also with Cr. As for now, little is known about most bacterial species thriving in such soils and even less about a core bacterial community - a set of taxa common to polluted soils. Therefore, we wanted to answer the question if such a set could be found in samples differing physicochemically and phytosociologically. To answer the question, we analyzed bacterial communities in three soil samples contaminated with $\mathrm{Pb}$ and $\mathrm{Zn}$ and two contaminated with $\mathrm{Cr}$ and lower levels of $\mathrm{Pb}$ and $\mathrm{Zn}$. The communities were assessed with 16S rRNA gene fragments pyrosequencing. It was found that the samples differed significantly and $\mathrm{Zn}$ decreased both diversity and
\end{abstract}

Electronic supplementary material The online version of this article (doi:10.1007/s00248-013-0344-7) contains supplementary material, which is available to authorized users.

M. Gołębiewski $(\bowtie) \cdot$ E. Deja-Sikora $\cdot$ A. Tretyn

Chair of Plant Physiology and Biotechnology, Nicolaus Copernicus

University, Lwowska 1, 87-100 Toruń, Poland

e-mail: mgoleb@biol.umk.pl

M. Gołębiewski · A. Tretyn

Centre of Modern Interdisciplinary Technologies, Nicolaus

Copernicus University, Wilenska 4, 87-100 Toruń, Poland

M. Gołębiewski • B. Wróbel

Institute of Oceanology PAS, Powstańców Warszawy 55, 81-712 Sopot, Poland

\section{B. Wróbel}

Evolutionary Systems Laboratory, Adam Mickiewicz University, Umultowska 89, Room S1, 61-614 Poznań, Poland

\section{Cichosz}

Department of Chemical Pro-ecological Processes, Nicolaus

Copernicus University, Gagarina 7, 87-100 Toruń, Poland species richness at species and family levels, while plant species richness did not correlate with bacterial diversity. In spite of the differences between the samples, they shared many operational taxonomic units (OTUs) and it was possible to delineate the core microbiome of our sample set. The core set of OTUs comprised members of such taxa as Sphingomonas, Candidatus Solibacter, or Flexibacter showing that particular genera might be shared among sites $\sim 40 \mathrm{~km}$ distant.

\section{Introduction}

Analysis of biodiversity in areas under anthropogenic pressure (e.g., pollution or climate change) allows to quantify the possibly detrimental effects of human activity on particular taxonomic groups. Due to the rapid response, microbial biodiversity may also be used to monitor the outcome of bioremediation/bioreclamation efforts [1].

A number of existing studies showed varying degree of heavy metals impact on soil bacteria. Frostegård and colleagues [2] found that $\mathrm{Cd}, \mathrm{Cu}, \mathrm{Ni}, \mathrm{Pb}$, and $\mathrm{Zn}$ influenced patterns of phospholipid fatty acids (PLFA) and decreased biomass and activity (measured as respiration) of microbial communities in forest and arable soils. However, determination which bacterial species or higher taxonomic units were affected was beyond the capabilities of this methodology. rRNA-based methods allowed for more detailed analyses; certain groups reported differential influence of metals on culturable and unculturable fractions of soil bacterial community $[3,4]$. Total community richness was found to be only moderately affected by heavy metals $[5,6]$, but Gans et al. found that the diversity in heavily polluted soils may constitute only $1 \%$ of that in pristine soils [7].

It is estimated that only $0.1-1 \%$ of soil bacteria are readily culturable $[8,9]$. This leads to the conclusion that culture- 
independent methods should be preferred, although some researchers disagree with this view claiming that the culturable subcommunity is the most active, and therefore the most important $[4,10,11]$.

Among the methods that can assess both culturable and unculturable bacteria, the majority is based on marker genes, such as $16 \mathrm{~S}$ rRNA or recA genes [12,13]. Next generation sequencing (NGS) quickly becomes the method of choice, due to the high data yield and relatively low costs of data generation. To date, several reports on soil bacterial communities analyzed via $16 \mathrm{~S}$ rRNA gene fragments pyrosequencing were published [14-17], but only a few of them were devoted to metals-contaminated soils. The dependence of bacterial diversity and species richness on the contamination was found in $\mathrm{Cd}, \mathrm{Pb}$, and $\mathrm{Zn}[18,19]$ as well as $\mathrm{Cr}$ and $\mathrm{As}[20]$ and $\mathrm{Cu}$ [19] contaminated soils. Metals caused decrease of diversity, increase of Proteobacteria, and decrease of Acidobacteria and Actinobacteria levels. However, when considered with other factors, they were not the most important variables shaping the community structure [19].

We wanted to see if bacterial communities in two soils, differently contaminated with heavy metals and varying in other physicochemical parameters as well as phytosociologically but coming from the same geographical region were similar. Basing on the shared operational taxonomic units (OTUs) set, we delineated a core microbiome of our samples, defined as the set of OTUs evenly distributed among all the samples and present at the percentage greater than $0.1 \%$.We looked also at the diversity, the species richness, and the community structure. To study the parameters of interest, barcoded libraries of V3-V4 16S rRNA gene fragments were pyrosequenced and between 15,000 and 20,000 raw reads from each sample were generated. We developed a bioinformatic pipeline based on MOTHUR [21] and used it to analyze the parameters mentioned above.

\section{Methods}

\section{Soil Samples}

Samples were collected at two sites in Southern Poland: near Olkusz $\left(50^{\circ} 17^{\prime} \mathrm{N}, 19^{\circ} 30^{\prime} \mathrm{E}\right)$, in the vicinity of a lead and zinc ore enrichment facility (specifically its flotation waste collector), and in Alwernia $\left(50^{\circ} 02^{\prime} \mathrm{N}, 19^{\circ} 31^{\prime} \mathrm{E}\right)$, near a chromium green-producing facility. The sampling points were located on public grounds, not protected by nature reserve or national park, and therefore no specific permission was required. The fieldwork did not involve any endangered or protected species.

Phytosociological analysis of the sampling sites was performed according to the Braun-Blanquet method [22]. Briefly, one phytosociological picture was taken at each site, then the plant species were identified and their coverage (in standard six-point Braun-Blanquet scale: +- - rare species, 1 - abundant species, coverage lower than $20 \%, 2$-very abundant species with coverage $<20 \%$ or abundant one with coverage between 20 and $25 \%, 3-25-50 \%$ coverage, 4-50-75\% coverage, 5-75-100\% coverage) was estimated.

Top soil from the 5-30-cm layer was collected in July 2009. Five subsamples were taken at each site at the four vertices and in the center of a $2.5-\mathrm{m}$ square. After visible plant fragments and large stones were removed, the subsamples were combined, and the sample was thoroughly mixed with a spade. After sampling, the soils were transferred to plastic bags which were sealed and stored in a cold room (at $9^{\circ} \mathrm{C}$ ) until analysis. DNA isolation (details below) was performed within 5 days, other analyzes until the end of 2009. The soil texture was assessed with the laser diffraction method on Analysette 22 (Fritsch, Germany). The organic matter and carbonates content were estimated by loss on ignition at 550 and $950^{\circ} \mathrm{C}$, respectively. The $\mathrm{pH}$ was measured in a $1: 10$ soilwater slurry with a digital $\mathrm{pH}$ meter (Elmetron, Poland). The metals content was analyzed by X-ray fluorescence (XRF), and their bioavailable concentrations were determined with atomic absorption spectrometry (AAS) after DETAPAC extraction [23]. The samples characteristics are summarized in Table 1, and the phytosociological analysis can be found in Table 2.

Analysis of 357f and 786r Primers Coverage and Specificity

Primers' coverage (percentage of bacterial sequences in a database from which the primer set generates amplicons) and specificity (percentage of nonbacterial sequences amplified by the primers) were assessed by TestProbe from the SILVA website (http://beta.arb-silva.de/search/testprobe; [24]) run on the SSU r114 database and by Ribosomal Database Project's tool ProbeMatch (http://rdp.cme.msu.edu/ probematch/search.jsp; [25]) run against the RDP 10 update 31 database. Both tools were run with two mismatches allowed and otherwise default settings, with the exception of using weighted mismatches in TestProbe. The parameters for the pair of primers were also assessed with ProbeMatch of RDP and TestPrime from SILVA [26].

\section{Isolation of Metagenomic DNA}

Metagenomic DNA was isolated from $30 \mathrm{~g}$ of homogenized soils with the method developed by Zhou and colleagues [27] modified to increase the yield of DNA and the spectrum of lysed bacteria. The modifications involved adding an enzymatic digestion (lysozyme and achromopeptidase) step before the SDS lysis and lowering the lysis temperature $\left(55^{\circ} \mathrm{C}\right.$ instead of $65^{\circ} \mathrm{C}$ ) [28]. Subsequently, the DNA was purified in two agarose gel electrophoresis steps, first using $0.7 \%$, and 
then in $1 \%$ agarose. Pure DNA was recovered from the gel with an agarose gel extraction kit (Roche). The quality of the preparations was assessed spectrophotometrically on NanoDrop ND-1000 (NanoDrop, Wilmington, DE).

PCR Amplification of 16S rRNA Gene Fragments and Pyrosequencing

A fragment of the 16S rRNA gene encompassing the V3 and $\mathrm{V} 4$ variable regions [29] was amplified with primers $357 \mathrm{f} \mathrm{(5^{ \prime }}$ CCT ACG GGA GGC AGC AG 3', [30]) and 786r (5' AC CAG GGT ATC TAA WCC 3', this work) with overhangs required for pyrosequencing. The forward primer was used in three versions differing in the multiplex identifier (MID) sequence between the A adaptor and the actual primer. The reaction mix contained the following: $1 \mathrm{ng}$ of template DNA, 10 pmol primers, $0.2 \mathrm{mM}$ dNTP, $1.5 \mathrm{mM} \mathrm{MgCl}_{2}, 0.2 \mathrm{U}$ of Taq polymerase, and the appropriate $1 \times$ buffer (Fermentas, Lithuania). The cycling conditions were as follows: $95^{\circ} \mathrm{C}$ for $5 \mathrm{~min}$, 30 cycles of: $95^{\circ} \mathrm{C}$ for $30 \mathrm{~s}, 52^{\circ} \mathrm{C}$ for $30 \mathrm{~s}, 72^{\circ} \mathrm{C}$ for $30 \mathrm{~s}$; and finally $72^{\circ} \mathrm{C}$ for $2 \mathrm{~min}$. The reactions were carried out in MasterCycler thermocycler (Eppendorf, Germany). Eight independent reactions were performed for each sample.

PCR products were purified with the DNA CleanUp kit (A\&A Biotechnology, Poland), pooled in equimolar amounts, vacuum dried, and either sent for sequencing at Max Planck Molecular Genetics Institute sequencing service (Berlin, Germany-Olkusz samples) or sequenced at the Chair of Genetics, University of Silesia (Katowice, Poland-Alwernia ones). Pyrosequencing was performed with the use of Titanium chemistry on GS FLX and GS Junior instruments (Roche, USA) as described in the manufacturer's protocols.

\section{Bioinformatic Analysis}

We developed a bash script that allowed a streamlined analysis of sequence data using MOTHUR v.1.30.2 [21] and R [31] and by calling other scripts in bash. The script took as the input an .sff file(s) (either a single one with all samples or many single-sample files) and a file containing information on the primers used for amplicons generation with optional barcodes (in the case of single .sff) or, in the case of multiple .sff files, additional file with sample names. The computations were parallelized where possible to speed up the analysis. The limits on the number of processors and the amount of RAM to be used in the clustering step could be set to allow running the script on multi-processors machines without consuming all the resources available.

The script can be run on any POSIX-compatible operating system, where installation of bash shell is possible. We ran the analyzes on a 48-core 256 GB RAM machine under control of the 64-bit version of Fedora 14 Linux, using eight cores and with limit of RAM amount set to $10 \mathrm{~GB}$. All the procedures 
Table 2 Phytosociological analysis of sampling points

\begin{tabular}{|c|c|c|c|c|c|}
\hline Sample & Phytosociological classification & $\begin{array}{l}\text { Plant sp. } \\
\text { richness }\end{array}$ & $\begin{array}{l}\text { Trees } \\
\text { coverage }\end{array}$ & $\begin{array}{l}\text { Herbaceous } \\
\text { plants coverage }\end{array}$ & Main species \\
\hline A1 & $\begin{array}{l}\text { No-rank Equisetum arvense } \\
\text { Class: Agropyretea intermedio-repentis }\end{array}$ & 12 & $0 \%$ & $15 \%+10 \%$ mosses & Equisetum arvense \\
\hline A2 & $\begin{array}{l}\text { Assoc.: Phleum pratense } \\
\text { Alliance: Cynosurion } \\
\text { Order: Arrhenatheretalia } \\
\text { Class: Molinio-Arrhenatheretea }\end{array}$ & 36 & $0 \%$ & $100 \%$ & Phleum pratense \\
\hline $\mathrm{O} 1$ & $\begin{array}{l}\text { Assoc.: Querco roboris-Pinetum } \\
\text { Alliance: Dicrano-Pinion } \\
\text { Order: Piceetalia abietis } \\
\text { Class: Vaccinio-Piceetaea }\end{array}$ & 35 & $65 \%$ & $80 \%$ & $\begin{array}{l}\text { Pinus sylvestris, Festuca ovina, } \\
\text { Leontodon hispidus, Rumex thyrsiflorus }\end{array}$ \\
\hline $\mathrm{O} 2$ & $\begin{array}{l}\text { Assoc.: Spergulo vernalis-Corynephoretum } \\
\text { Alliance: Corynephorion canescentis } \\
\text { Order: Corynephoretalia canescentis } \\
\text { Class: Koelerio-Corynephoretea }\end{array}$ & 14 & $5 \%$ (shrubs) & $20 \%$ & Pinus sylvestris, Corynephorus canescens \\
\hline $\mathrm{O} 3$ & $\begin{array}{l}\text { No-rank Gypsophila fastigiata } \\
\text { Class: Koelerio-Corynephoretea }\end{array}$ & 14 & $0 \%$ & $15 \%$ & Gypsophila fastigiata \\
\hline
\end{tabular}

described below were pipelined in this script, available from the authors on request. The actual parameters for all steps of the pipeline can be found in Supplementary Materials.

Pyrosequencing adaptor and MID sequences were removed from the Olkusz reads by the sequencing center, and quality trimming was performed for separate sample files. For the Alwernia samples, a single .sff file was obtained, and the trimming was done accordingly. Quality trimming was performed with the AmpliconNoise algorithm [32] implemented in MOTHUR's shhh.flows. The reads were then dereplicated, aligned against the SILVA template alignment, and screened for those covering the desired alignment region. The gap-only and terminal gap-containing columns were filtered out of the alignment and putative chimeras were identified with the uchime algorithm [33] and removed. Finally, the sequencing noise was further reduced via single-linkage pre-clustering [34]. Then, the high-quality reads were down-sampled to the smallest sample size and (1) classified with naïve Bayesian classifier implemented in MOTHUR (classify.seqs) using SILVA taxonomy provided by the authors of the program on the webpage www.mothur.org/w/images/9/98/Silva.bacteria. zip, as well as (2) a distance matrix was calculated, and OTUs were constructed by average neighbor clustering. Sequences were regarded successfully classified at a given level if their bootstrap support was greater than $80 \%$.

\section{Species Richness and Diversity Analyzes}

Species richness was assessed with Chaol [35] and ACE [36] indices, as well as with catchall v3.0 [37]. Phylogenetic diversity was measured according to the methodology of Faith and coworkers [38] (MOTHUR's command "phylo.diversity"). The estimators were calculated for five subsamples containing
1,500 sequences drawn randomly from each group and averaged to yield the final values.

An averaged shared OTU table was prepared from the subsamples (for details, see Supplementary Materials).

Morisita-Horn [39] and Bray-Curtis [40] dissimilarities were calculated for all the pairs of samples via dist.shared command of MOTHUR. They were visualized as heatmaps with the use of the heatmap.sim command. Venn diagrams were prepared from the shared OTU table using a custom Perl script.

To check if the communities differed significantly, the parsimony [41] and weighted UniFrac [42] tests were employed. The MOTHUR commands parsimony and unifrac.weighted were used, respectively. The tests were run on a phylogenetic tree generated from the same distance matrix that served for the OTU construction, with the use of the relaxed neighbor joining algorithm of clearcut [43] implemented in MOTHUR.

\section{Statistical Analysis}

Statistical analysis was performed in R 2.15.2 [31], using vegan [44] (redundancy analysis (RDA) with significance testing by permutation-ANOVA) and Hmisc [45] packages (Spearman's correlation in rcorr).

\section{Core Microbiome Delineation}

The "core microbiome," as defined by Turbaugh and coworkers [46], would consist of the OTUs that were present in all the samples. We added two conditions here: (1) the OTUs should be present in roughly equal amounts and (2) the frequency of reads has to be $>0.1 \%$ in each sample $(>2$ reads). OTUs meeting the conditions were identified by 
calculation of Shannon's evenness, treating the samples as taxa and reads as individuals and eliminating those with two or less reads in any sample. The OTUs with the value greater than 0.9 were regarded "evenly distributed" and assigned to the core microbiome.

\section{Results}

\section{Sites and Soils Characteristics}

In this study, we analyzed the bacterial community structure and species richness in three soil samples from Olkusz and two from Alwernia, both towns located in the Malopolska province of Poland. The soils came from the area lying in the vicinity of a flotation waste pond of a zinc and lead ore enrichment facility (Olkusz) and from the grounds adjacent to a factory producing chromium-based pigments (Alwernia).

The samples differed from each other, both in terms of plant species richness ( $\mathrm{A} 1$ being the least rich, and $\mathrm{A} 2$ being the most) and phytosociological classification (Table 2). Also, the ground coverage by plants varied greatly, from almost $0 \%$ for $\mathrm{O} 3$ to $100 \%$ for A2. Two samples were classified as norank associations (A1 - no rank Equisetum arvense, $\mathrm{O} 3$ - no rank Gypsophila fastigiata), while the remaining three belonged to syntaxons well placed in the hierarchy (Table 2).

The three Olkusz samples appeared to be sandy (Table 1), the organic matter content varied between $19.90 \%(\mathrm{O} 1)$ and $3.82 \%(\mathrm{O} 3)$, and the inorganic carbon (carbonates) content was below $1 \%$ in $\mathrm{O} 2$ and $\mathrm{O} 3$, while it was over $30 \%$ in $\mathrm{O} 3$. High $\mathrm{C}_{\text {org }}$ content in the $\mathrm{O} 1$ and $\mathrm{O} 2$ samples was due to the addition of peat to the upper layer of soil in an effort to immobilize heavy metal ions to allow land reclamation, which was done in 1990s [47]. High level of carbonates in O3 was brought about by dolomite, which was the main component of flotation waste. The $\mathrm{pH}$ was close to neutral in all samples. Slightly alkaline $\mathrm{pH}$ in the $\mathrm{O} 3$ sample might have resulted from the high dolomite content and the remnants of the flotation reagents (xanthates) leaking from the pond. The organic matter content was 2.82 and $4.62 \%$ in A1 and A2, respectively, the carbonates were low, and the $\mathrm{pH}$ was close to neutral.

The samples were only moderately contaminated with $\mathrm{Cd}$ (3.4-4.2 mg kg ${ }^{-1}$ total conc., $2.1-2.5 \mathrm{mg} \mathrm{kg}^{-1}$ bioavailable conc.-Table 1), and the sites did not differ much in the concentration of this metal. The levels of $\mathrm{Pb}$ and, particularly, $\mathrm{Zn}$ were high in the Olkusz samples, reaching $1,097 \mathrm{mg} \mathrm{kg}^{-1}$ $(\mathrm{Pb})$ and 2,002 $\mathrm{mg} \mathrm{kg}^{-1}(\mathrm{Zn})$ total concentration at $\mathrm{O}$, and were much lower in Alwernia ones. The opposite pattern was found for $\mathrm{Cr}$, whose concentration was highest in $\mathrm{A} 2$ $\left(760 \mathrm{mg} \mathrm{kg}^{-1}\right.$ ). Bioavailable concentrations of the metals were at the level of $70 \%$ of the total concentrations. It seems that in the Olkusz samples, $\mathrm{Pb}$ and $\mathrm{Zn}$ were the main contaminants which might have influenced bacterial communities. In the Alwernia ones, $\mathrm{Cr}$ and $\mathrm{Zn}$ were the dominant pollutants, while $\mathrm{Cd}$ could be neglected in all the samples due to its low concentration.

\section{Primers' Coverage and Specificity}

The 357 f primer was highly specific, as only $2.5 \%$ of matches came from Archaea according to RDP and $20.6 \%$ were not from bacteria according to SILVA. It had also high coverage, as it amplified over $99.4 \%$ (RDP) and $96.7 \%$ (SILVA) of bacterial sequences. The 786r primer also performed well, having 99.3 and $97.2 \%$ of coverage among bacteria (according to RDP and SILVA, respectively) and slightly lower specificity (5.4 and $26.1 \%$ of matches were nonbacterial in RDP and SILVA). Both tools reported a fair coverage of Archaea by the primers (up to $86.6 \%$ for Euryarchaeota), but when no mismatches were allowed, these matches disappeared.

As a pair, the primers were highly specific for bacteria (2.9 and $25.7 \%$ nonbacterial matches in RDP and SILVA, respectively) and the coverage was also high (98.8 and $88.7 \%$ ). The values reported were calculated excluding sequences lacking the 357-786 region.

\section{Sequencing}

The DNA preparations were of high quality, as their A260/280 ratios were $\sim 1.8$ for all samples and A260/230 at $\sim 2$ indicating high purity. All of them performed well as PCR templates. In total, 66,385 reads were obtained (Table 3), out of which $25,808(38.9 \%)$ met the quality criteria. The 2,376 potential chimeras were removed, and $23,432(35.3 \%$ of the total number) high-quality nonchimeric reads were included in the downstream analysis. The median of read length was $250 \mathrm{bp}$ and the mean was $255 \mathrm{bp}$. All the reads were successfully classified at the domain (all of them came from bacteria) and phylum level (bootstrap support $>80 \%$ ), for lower taxonomic levels, the percentage of unclassified sequences increased, to reach $50.5 \%$ for genus. The reads generated in this project were deposited in the NCBI's SRA database under SRA IDs SRA024301.1 (Olkusz) and SRA059341.1 (Alwernia).

\section{Community Species Richness and Diversity Indices}

The communities were moderately sampled, indicating that much more reads would be required to capture all the diversity (Fig. 1). The Alwernia samples were more diverse than the Olkusz ones, which was particularly visible at the 0.10 level (Table 4). Bacterial diversity in the Olkusz soils decreased with increasing concentration of $\mathrm{Pb}$ and $\mathrm{Zn}(\mathrm{O} 2>\mathrm{O} 1>\mathrm{O} 3)$, while A1 was more diverse than A2 in spite of the higher 
Table 3 Sequencing statistics

\begin{tabular}{|c|c|c|c|c|c|c|c|}
\hline \multirow[t]{2}{*}{ Sample } & \multirow[t]{2}{*}{ Raw reads no. } & \multicolumn{2}{|c|}{ High-quality reads } & \multicolumn{2}{|l|}{ Chimeras } & \multicolumn{2}{|c|}{ High-quality non-chimeric reads } \\
\hline & & Number & $\%^{\mathrm{a}}$ & Number & $\%^{\mathrm{b}}$ & Number & $\%{ }^{\mathrm{a}}$ \\
\hline A1 & 4,235 & 3,054 & $72.1 \%$ & 422 & $13.8 \%$ & 2,632 & $62.1 \%$ \\
\hline $\mathrm{A} 2$ & 5,947 & 4,229 & $71.1 \%$ & 783 & $18.5 \%$ & 3,446 & $57.9 \%$ \\
\hline $\mathrm{O} 1$ & 15,967 & 7,474 & $46.8 \%$ & 412 & $5.5 \%$ & 7,062 & $44.2 \%$ \\
\hline $\mathrm{O} 2$ & 17,522 & 6,215 & $35.5 \%$ & 363 & $5.8 \%$ & 5,852 & $33.4 \%$ \\
\hline $\mathrm{O} 3$ & 22,714 & 4,836 & $21.2 \%$ & 396 & $8.2 \%$ & 4,440 & $19.5 \%$ \\
\hline Total & 66,385 & 25,808 & $38.9 \%$ & 2376 & $9.2 \%$ & 23,432 & $35.3 \%$ \\
\hline
\end{tabular}

${ }^{\text {a }}$ Percent of raw reads

${ }^{\mathrm{b}}$ Percent of high-quality reads

richness and diversity, and the correlation seemed to be non-

contamination level. The rarefaction analysis (Fig. 1) gave results similar to the comparison of Shannon's H' (Table 5). Evenness in all samples was close to 0.9 for the 0.03 clustering level and in the range $0.7-0.8$ for the 0.10 level, the highest values were observed in $\mathrm{A} 1$.

Both the observed and estimated total richness was higher in the Alwernia communities than in the Olkusz ones (Table 4). At the 0.03 dissimilarity level, all the methods predicted the highest richness in $\mathrm{A} 1$, while at the 0.10 level, only catchall predicted a greater number of OTUs in A2 than in A1. The parametric methods, such as catchall, should be independent of the community coverage, therefore they could be trusted more than the nonparametric estimators. The collectors curves for the Chao 1 and ACE indices showed no saturation (Fig. S2), so one would expect that the values of these estimators would increase with the sampling effort. In other words, they should not be treated as the true richness estimations.

The estimated number of OTUs in the least rich sample (O3) was about five times lower than in the richest one (A1 or A2). As all the methods used predicted that the richness was smallest in the most contaminated sample (O3), it might mean that species richness was affected by heavy metals contamination. Indeed, regression analysis showed that the $\mathrm{Zn}$ concentration negatively correlated with all estimators of species linear (Spearman's rank correlation, $p<0.05$, Table 6, Supplementary Fig. S1). However, due to the low number of samples, such results should be treated cautiously, in spite of their high statistical significance. No other variables, including the phosphorus concentration and the plant species richness, correlated with bacterial diversity (RDA model's $p>0.05$ ) or species richness measures (Spearman's rank correlation, $p>0.05$, Table S3).

\section{Bacterial Community Structure}

All the reads were assigned to bacteria. Proteobacteria were the most abundant phylum in all five samples (27.5$49.5 \%$-Fig. 2, Table S1), in the Alwernia ones and O3, they were followed by Acidobacteria, while in $\mathrm{O} 1$ and $\mathrm{O} 2$ by Actinobacteria. Other major phyla were Bacteroidetes, Chloroflexi, and Gemmatimonadetes. The most abundant classes were Alphaproteobacteria, Actinobacteria, Acidobacteria, Gammaproteobacteria, Sphingobacteria, and Betaproteobacteria (Fig. 3b). The most abundant genera $(>100$ reads across all samples) collectively comprised $43.1 \%$ of all reads, and their percentage varied from $35.8 \%(\mathrm{O} 2)$ to $55.4 \%(\mathrm{O} 3)$ (Fig. 3, details in Table S2).
Fig. 1 Rarefaction curves. a 0.03 dissimilarity level, b 0.10 dissimilarity level

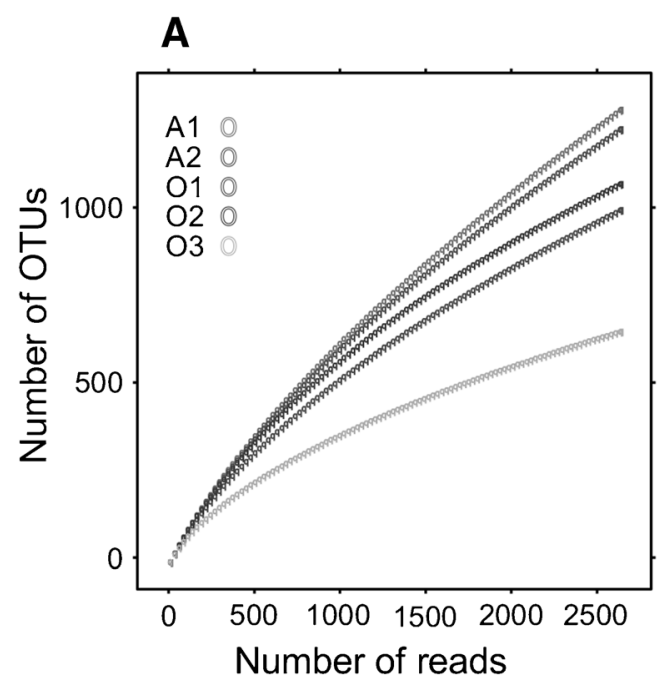


Table 4 Species richness estimators

\begin{tabular}{|c|c|c|c|c|c|c|c|c|}
\hline \multirow[t]{2}{*}{ Sample } & \multicolumn{2}{|c|}{ OTUs observed } & \multicolumn{2}{|l|}{ Chaol } & \multicolumn{2}{|l|}{$\mathrm{ACE}$} & \multicolumn{2}{|c|}{ Catchall $^{\mathrm{b}}$} \\
\hline & $0.03^{\mathrm{a}}$ & $0.10^{\mathrm{a}}$ & 0.03 & 0.10 & 0.03 & 0.10 & 0.03 & 0.10 \\
\hline A1 & 858 & 386 & $\mathbf{3 , 0 2 5}(2,536-3,657)$ & $\mathbf{9 8 1}(790-1,261)$ & $\mathbf{5 , 1 8 8}(4,747-5,679)$ & $\mathbf{1 , 5 5 4}(1,381-1,758)$ & 8,637 & 1,747 \\
\hline $\mathrm{A} 2$ & 826 & 342 & $2,530(2,150-3,019)$ & $881(697-1,160)$ & $4,515(4,139-4,934)$ & $1,347(1,195-1,527)$ & 6,662 & 1,900 \\
\hline $\mathrm{O} 1$ & 699 & 263 & $1,589(1,383-1,858)$ & $436(372-536)$ & $2,596(2,361-2,864)$ & $576(504-670)$ & 2,558 & 610 \\
\hline $\mathrm{O} 2$ & 749 & 312 & $1,728(1,507-2,013)$ & $523(448-640)$ & $2,723(2,485-2,993)$ & $637(569-723)$ & 3,239 & 900 \\
\hline $\mathrm{O} 3$ & 476 & 224 & $1,069(903-1,301)$ & $402(330-521)$ & $1,768(1,589-1,977)$ & $571(495-667)$ & 1,934 & 546 \\
\hline
\end{tabular}

Each value is a mean of five obtained for random subsamples of equal size, $95 \%$ confidence intervals are in parentheses. Highest values are in boldface ${ }^{a}$ Dissimilarity level for OTU construction

${ }^{\mathrm{b}}$ Due to a bug in catchall there is no confidence intervals for the estimations

The four most abundant ones were uncultured members of Acidobacteriaceae, Gemmatimonadaceae, Nitrosomonadaceae, and Xanthobacteraceae. The Alwernia samples contained more representatives of an uncultured genus of Acidobacteriaceae family and Geobacter (Deltaproteobacteria, Geobacteraceae) than the Olkusz ones, while genus Solirubrobacter (Actinobacteria, Solirubrobacteraceae) was more abundant in the Olkusz soils. The O3 sample contained a high proportion of sulfur oxidizing bacteria of genera Beggiatoa (Gammaproteobacteria, Thiotrichaceae) and Thiobacillus (Betaproteobacteria, Hydrogenophilaceae) that probably utilized sulfides present in mine tailings, mainly pyrite, and possibly organosulfur compounds used in the flotation process (xanthates).

Influence of environmental variables on the community structure was assessed with $\mathrm{RDA} . \mathrm{Zn}, \mathrm{Pb}, \mathrm{Cr}$, and $\mathrm{pH}$ were found to be significantly correlated with the community structure both on the 0.10 and 0.03 clustering levels $(p<0.05$, see Fig. S3). Notably, the $\mathrm{P}$ concentration and plant species richness did not influence the communities under study.

\section{Comparison of Communities}

To measure the "overlap" between the communities in the samples, an abundance-based index (Morisita-Horn-M-H), as well as an incidence-based one (Bray-Curtis-B-C) were used to calculate distances and community similarity heatmaps were generated (Fig. 4). At both clustering levels, the B-C similarities were smaller than the $\mathrm{M}-\mathrm{H}$ ones, indicating that the structures of the abundant OTUs subcommunities were more similar than the rare OTUs communities structures. In other words, the rare OTUs were unique for each sample, while the abundant ones were more likely shared. Regardless of the clustering level and the similarity measure, $\mathrm{O} 1$ and $\mathrm{O} 2$ appeared to be the most similar samples, A1 and A2 formed another pair, while $\mathrm{O} 3$ showed little similarity to other ones.

The community overlaps were depicted as Venn diagrams (Fig. 5). The results corroborated analyzes of the M-H and B-C similarities presented above: $\mathrm{O} 1$ and $\mathrm{O} 2$ shared almost identical number of OTUs as A1 and A2. Surprisingly, in spite of differences in the physicochemical features and the plant vegetation between sampling sites, many of the OTUs were shared by all five samples, particularly at the 0.10 clustering level (37 and 68 at 0.03 and 0.10 level, respectively). The percentage of sequences belonging to these OTUs reached $12 \%$ at the 0.03 level and almost $60 \%$ at the 0.10 level.

The statistical significance of differences in community structure were assessed via the parsimony and weighted UniFrac tests. Both methods showed that all the pairs of samples differed significantly $(p<0.001)$.

Identification of OTUs Shared by all Samples — "Core Microbiome"

To learn which taxons were shared, consensus taxonomy was constructed for each OTU and the ones present in all the
Table 5 Diversity and evenness estimators

Each value is an average of five coming from random subsamples of size $1,500.95 \%$ confidence intervals are given in parentheses

${ }^{a}$ Dissimilarity level for OTU construction

\begin{tabular}{|c|c|c|c|c|c|}
\hline \multirow[t]{2}{*}{ Sample } & \multicolumn{2}{|l|}{ Shannon's H' } & \multicolumn{2}{|c|}{ Shannon's evenness } & \multirow[t]{2}{*}{ Phylodiversity } \\
\hline & $0.03^{\mathrm{a}}$ & $0.10^{\mathrm{a}}$ & 0.03 & 0.10 & \\
\hline A1 & $6.367(6.309-6.425)$ & $4.984(4.908-5.060)$ & 0.943 & 0.837 & 53,34 \\
\hline A2 & $6.309(6.249-6.368)$ & $4.800(4.723-4.878)$ & 0.939 & 0.823 & 49.14 \\
\hline $\mathrm{O} 1$ & $5.978(5.909-6.047)$ & $4.280(4.194-4.366)$ & 0.913 & 0.768 & 40,32 \\
\hline $\mathrm{O} 2$ & $6.196(6.137-6.254)$ & $4.810(4.738-4.883)$ & 0.936 & 0.838 & 45,63 \\
\hline $\mathrm{O} 3$ & $5.321(5.247-5.395)$ & $4.169(4.087-4.251)$ & 0.863 & 0.771 & 30,66 \\
\hline
\end{tabular}


Table 6 Correlation of zinc concentration with bacterial species richness and diversity estimators

Spearman's correlation coefficient and $p$ value

Sp. observed (OTUs 0.03)

Chao1 (OTUs 0.03)

ACE (OTUs 0.03)

Shannon's H' (OTUs 0.03)

Sp. observed (OTUs 0.10)

Chao1 (OTUs 0.10)

ACE (OTUs 0.10)

Shannon's H' (OTUs 0.10)

Phylodiversity

$$
\begin{aligned}
& \rho=-1, p=0 \\
& \rho=-1, p=0 \\
& \rho=-1, p=0 \\
& \rho=-1, p=0 \\
& \rho=-1, p=0 \\
& \rho=-1, p=0 \\
& \rho=-1, p=0 \\
& \rho=-0.90, p=0.03 \\
& \rho=-1, p=0
\end{aligned}
$$

samples were identified with an in-house developed Perl script.

At the 0.03 level, the shared OTUs belonged mainly to Alphaproteobacteria (Table S3) and Acidobacteria, with KD496 (Chloroflexi), Actinobacteria, and Betaproteobacteria being less frequent. The largest shared OTUs were Otu5473 (an uncultured member of Xanthobacteraceae), Otu5214 (Sphingomonas), and Otu4909 (Candidatus Solibacter).
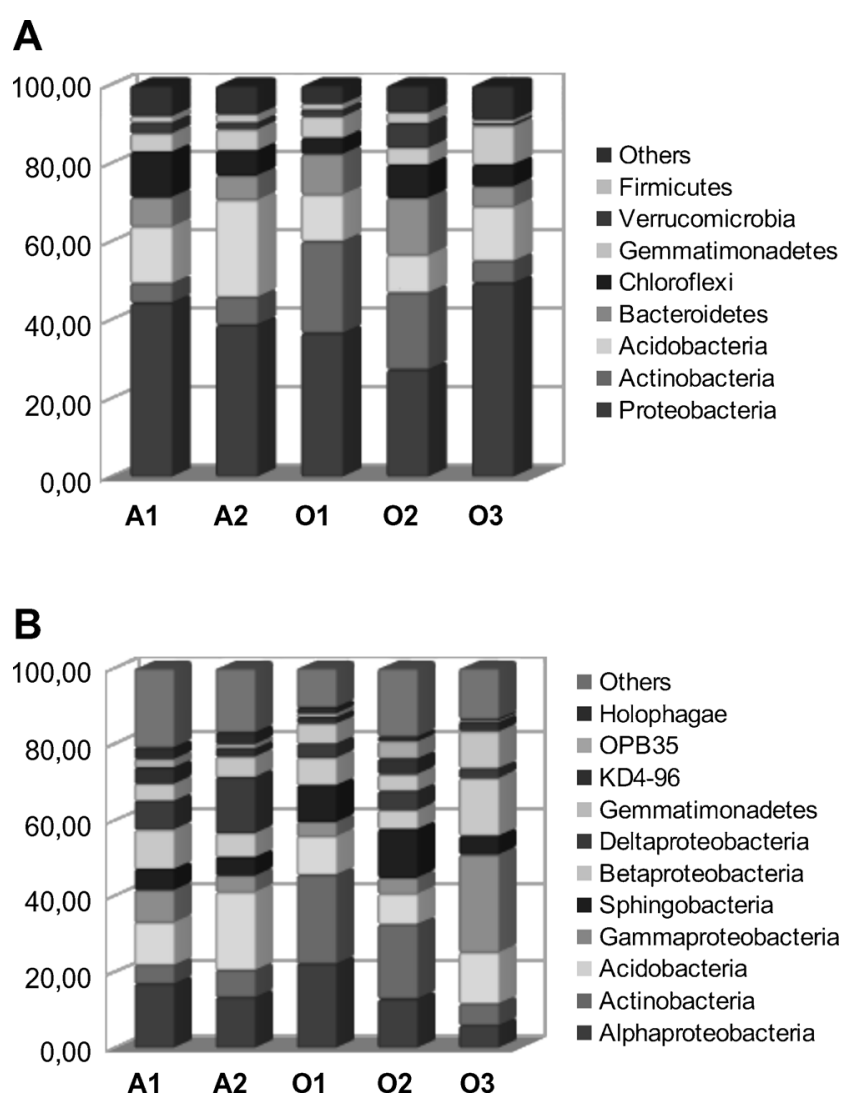

Fig. 2 Bacterial community structure in samples. a Phylum level, b class level
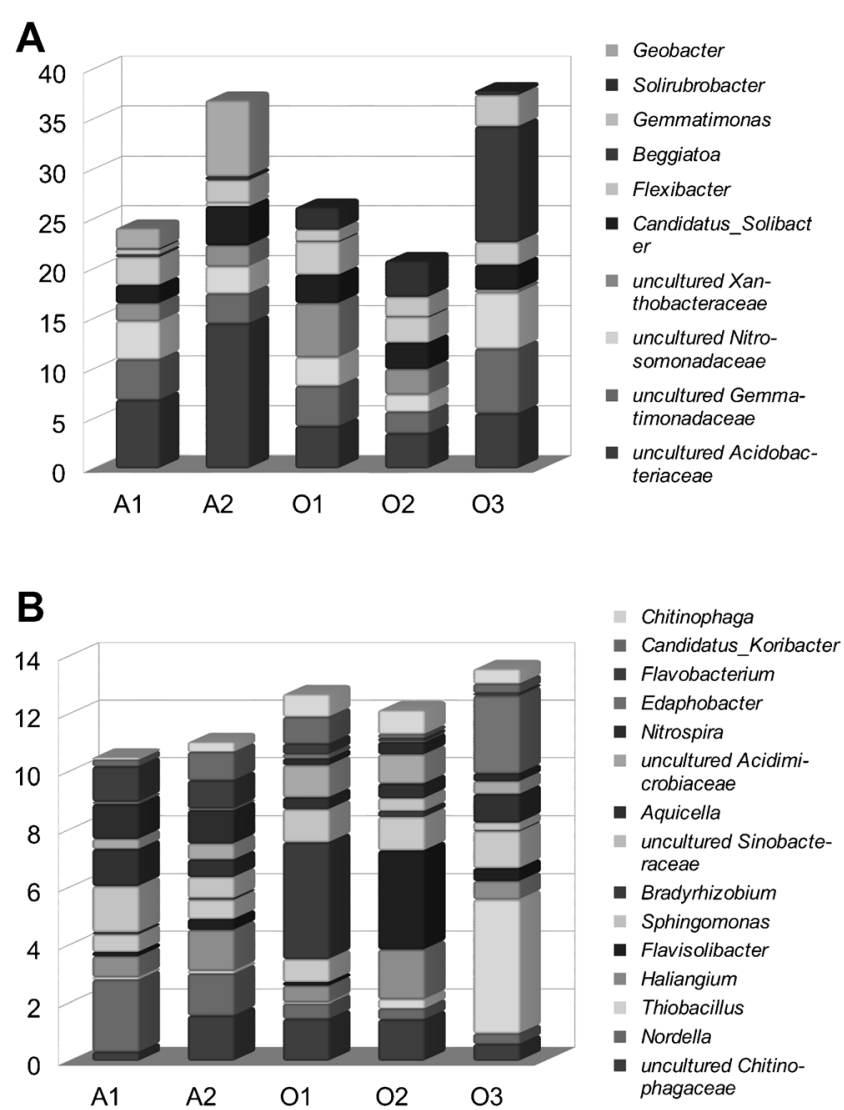

Fig. 3 Most abundant genera in samples. a 10 genera of highest total abundance; b next 15 genera

At the 0.10 level, the picture was similar (Table S4); however, members of the Bacteroidetes phylum (order Sphingomonadales) were more numerous than Chloroflexi. When a definition of core microbiome given in "Methods" was used, at the 0.03 level, there were four "core" OTUs (Table 7), two belonging to Alphaproteobacteria (genera Sphingomonas and Holospora), one to Acidobacteria (unclassified Acidobacteriaceae) and one to Chloroflexi (members of KD4-96). At the higher level, there were 21 core OTUs (Table 8), coming mostly from Sphingobacteria (mainly Flexibacter and members of Chitinophagaceae), Alphaproteobacteria (members of Sphingomonadaceae and Rhodospirillales), KD4-96 (phylum Chloroflexi), and Betaproteobacteria (members of Nitrosomonadaceae, Comamonadaceae, TRA3-20 and SC-I-84).

\section{Discussion}

In spite of the high level of soils contamination with $\mathrm{Pb}$ and $\mathrm{Zn}$, the species richness, diversity, and evenness of bacterial communities under study were similar or slightly lower than those found in studies of unpolluted soils (e.g., $[16,17])$. Hur and coworkers [18] found much lower numbers of OTUs in $\mathrm{Cd}, \mathrm{Pb}$, and $\mathrm{Zn}$ polluted soils (less than 300 observed OTUs at 
Fig. 4 Community distance heatmaps. Darker shade means greater distance (lower similarity). Light grey small distances (greater similarity), dark grey - greater distances (lower similarity). Heatmaps based on Bray-Curtis dissimilarity a at 0.03 dissimilarity level and $\mathbf{b}$ at 0.10 dissimilarity level; Heatmaps based on Morisita-Horn dissimilarity $\mathbf{c}$ at 0.03 dissimilarity level and $\mathbf{d}$ at 0.10 dissimilarity level
A

A

$\mathrm{A} 1$

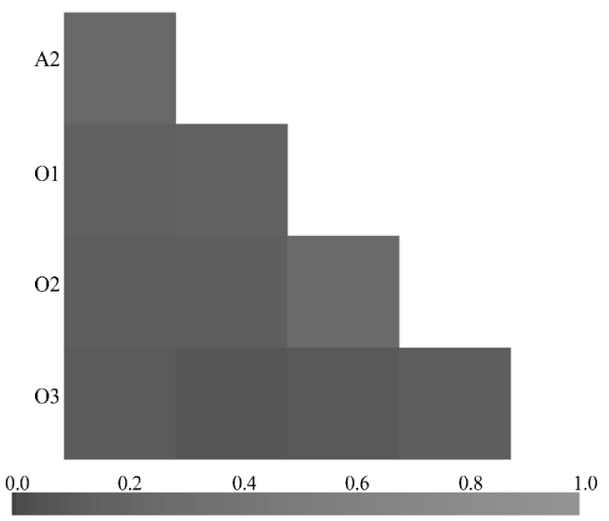

C

C

A1

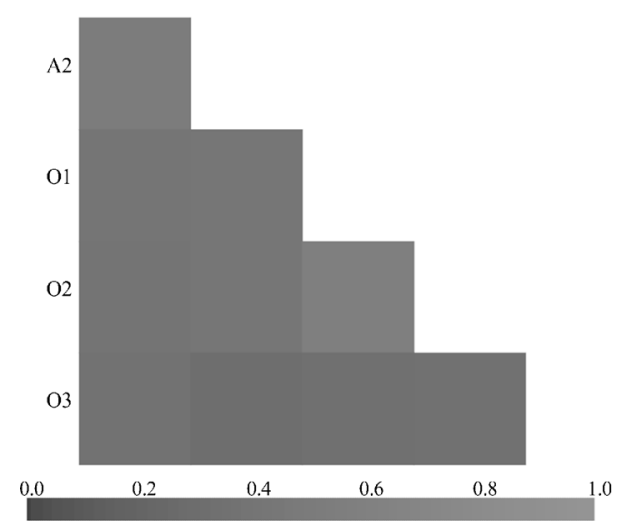

B

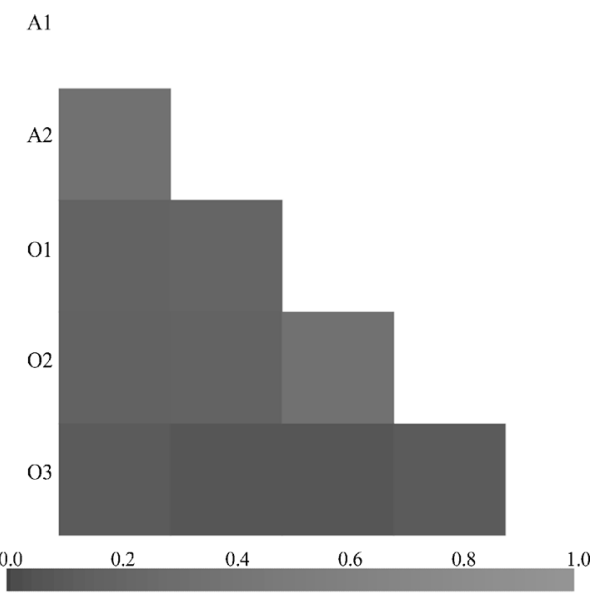

D

$\mathrm{A} 1$

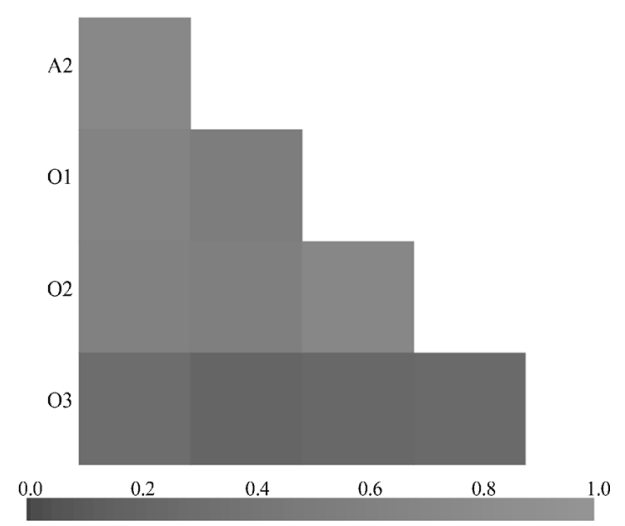

the 0.03 clustering level); however, the soils they analyzed were much more contaminated with $\mathrm{Cd}\left(>300 \mathrm{mg} \mathrm{kg}^{-1}\right)$ and less with $\mathrm{Zn}$. In spite of the small number of samples, we found a significant negative correlation between bioavailable
Zn concentration and all measures of species richness, Shannon's diversity as well as evenness, which was also similar to Hur's results [18]. Interestingly, Berg and colleagues [48] found that a long term $\mathrm{Cu}$ exposure changes the
Fig. 5 Venn diagrams of shared OTUs. a 0.03 dissimilarity level, b 0.10 dissimilarity level
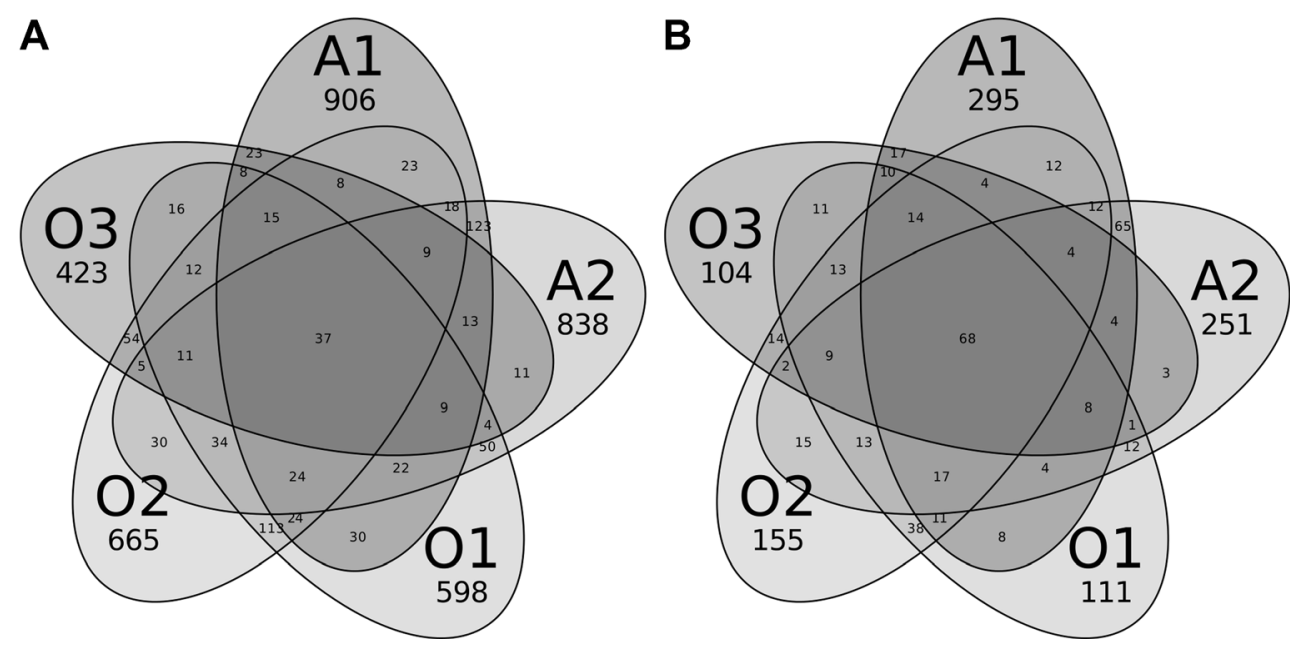
Table 7 Consensus taxonomies for 0.03 level core microbiome OTUs

\begin{tabular}{|c|c|c|c|c|c|c|c|c|}
\hline & A1 & $\mathrm{A} 2$ & $\mathrm{O} 1$ & $\mathrm{O} 2$ & $\mathrm{O} 3$ & $E^{a}$ & Total & Taxonomy \\
\hline Otu4707 & 4 & 3 & 4 & 6 & 6 & 0,979 & 23 & $\begin{array}{l}\text { Proteobacteria; Alphaproteobacteria; Rickettsiales; } \\
\text { Holosporaceae; Holospora; }\end{array}$ \\
\hline Otu5214 & 13 & 26 & 24 & 36 & 41 & 0,960 & 140 & $\begin{array}{l}\text { Proteobacteria; Alphaproteobacteria; Sphingomonadales; } \\
\text { Sphingomonadaceae; Sphingomonas; }\end{array}$ \\
\hline Otu3722 & 11 & 3 & 12 & 4 & 9 & 0,925 & 39 & Chloroflexi;KD4-96; \\
\hline Otu4868 & 6 & 17 & 18 & 15 & 3 & 0,903 & 59 & Acidobacteria; Acidobacteria; Acidobacteriales; Acidobacteriaceae \\
\hline
\end{tabular}

The numbers of reads in each sample and the total number are reported

${ }^{a}$ Shannon evenness showing how evenly the reads were distributed among samples

bacterial community structure, but not its diversity and species richness, demonstrating that various metals influence the communities differently. Similar observations were made by Chodak et al. [20].

Other metals did not correlate with the diversity variables, which might have been caused by the low concentration (cadmium) or the relatively low toxicity (chromium and lead). We did not measure $\mathrm{Cr}(\mathrm{VI})$ level, which is the most toxic species of this metal, but the lack of correlation with diversity and richness might indicate that the concentration of chromates was low in our samples. Sheik and coworkers [20] found that $\mathrm{Cr}(\mathrm{VI})$ significantly impacted both the diversity and the community structure, lowering the former as well as the species richness.

Interestingly, the plant species richness did not seem to correlate with the bacterial diversity and richness. However,

Table 8 Consensus taxonomies for 0.10 level core microbiome OTUs

\begin{tabular}{|c|c|c|c|c|c|c|c|c|}
\hline & A1 & $\mathrm{A} 2$ & $\mathrm{O} 1$ & $\mathrm{O} 2$ & $\mathrm{O} 3$ & $E^{a}$ & Total & Taxonomy \\
\hline Otu1237 & 4 & 8 & 9 & 9 & 8 & 0.979 & 38 & WCHB1-60; \\
\hline Otu1558 & 15 & 6 & 8 & 7 & 6 & 0.956 & 42 & Proteobacteria; Gammaproteobacteria; Legionellales; Coxiellaceae; Aquicella; \\
\hline Otu1464 & 9 & 21 & 3 & 16 & 12 & 0.912 & 61 & $\begin{array}{l}\text { Proteobacteria; Deltaproteobacteria; Myxococcales; Nannocystineae; } \\
\text { Haliangiaceae; Haliangium; }\end{array}$ \\
\hline Otu1410 & 11 & 10 & 9 & 7 & 4 & 0.969 & 41 & Proteobacteria; Deltaproteobacteria;GR-WP33-30;uncultured; \\
\hline Otu1537 & 21 & 3 & 13 & 20 & 14 & 0.921 & 71 & Proteobacteria; Betaproteobacteria; TRA3-20; \\
\hline Otu1534 & 11 & 22 & 7 & 10 & 15 & 0.953 & 65 & Proteobacteria; Betaproteobacteria;SC-I-84; \\
\hline Otu1572 & 41 & 21 & 23 & 25 & 53 & 0.957 & 163 & $\begin{array}{l}\text { Proteobacteria; Betaproteobacteria; Nitrosomonadales; } \\
\text { Nitrosomonadaceae;uncultured; }\end{array}$ \\
\hline Otu1489 & 11 & 19 & 18 & 4 & 6 & 0.909 & 58 & Proteobacteria; Betaproteobacteria; Burkholderiales; Comamonadaceae; \\
\hline Otu1428 & 37 & 46 & 36 & 74 & 48 & 0.977 & 241 & Proteobacteria; Alphaproteobacteria; Sphingomonadales; Sphingomonadaceae; \\
\hline Otu1248 & 10 & 5 & 3 & 5 & 13 & 0.919 & 36 & Proteobacteria; Alphaproteobacteria; Rickettsiales; Holosporaceae; Holospora; \\
\hline Otu1434 & 35 & 38 & 45 & 36 & 8 & 0.938 & 162 & Proteobacteria; Alphaproteobacteria; Rhodospirillales; \\
\hline Otu1574 & 7 & 18 & 13 & 26 & 13 & 0.948 & 77 & Proteobacteria; Alphaproteobacteria; Rhodospirillales; \\
\hline Otu1524 & 12 & 23 & 19 & 19 & 3 & 0.916 & 76 & Proteobacteria; Alphaproteobacteria; Rhizobiales; Methylocystaceae;uncultured; \\
\hline Otu1557 & 10 & 13 & 18 & 17 & 3 & 0.926 & 61 & Proteobacteria; Alphaproteobacteria; Caulobacterales; Caulobacteraceae; \\
\hline Otu1531 & 7 & 4 & 4 & 4 & 3 & 0.973 & 22 & Chloroflexi;TK10; \\
\hline Otu1522 & 28 & 19 & 11 & 14 & 6 & 0.928 & 78 & Chloroflexi;S085; \\
\hline Otu1594 & 101 & 56 & 45 & 59 & 55 & 0.973 & 316 & Chloroflexi;KD4-96; \\
\hline Otu1504 & 20 & 20 & 10 & 20 & 25 & 0.977 & 95 & Candidate_division_TM7; \\
\hline Otu1589 & 74 & 11 & 96 & 61 & 58 & 0.915 & 300 & Bacteroidetes; Sphingobacteria; Sphingobacteriales; Cytophagaceae; Flexibacter; \\
\hline Otu1573 & 23 & 79 & 79 & 140 & 40 & 0.902 & 361 & Bacteroidetes; Sphingobacteria; Sphingobacteriales; Chitinophagaceae; \\
\hline Otu1470 & 42 & 109 & 90 & 72 & 54 & 0.966 & 367 & $\begin{array}{l}\text { Acidobacteria; Acidobacteria; Acidobacteriales; Acidobacteriaceae; } \\
\text { Candidatus_Solibacter; }\end{array}$ \\
\hline
\end{tabular}

The numbers of reads in each sample and total number are reported

${ }^{a}$ Shannon's evenness showing how evenly the reads were distributed among samples 
it might be hypothesized that specific plant species influenced these parameters. Which species did that and the kind of the influence remains to be elucidated.

The species richness and the diversity was higher in the Alwernia soils than in the Olkusz ones. The reason for this might be the soil texture, as there are evidences that higher clay content promotes bacterial diversity [49,50], or OM and $\mathrm{Cr}$, which seem to be positively correlated in our samples.

The samples were taken in a way to avoid sampling rhizosphere communities (depth 5-30 cm, roots removed with soil sticking to them); however, in the case of the Olkusz ones, it was more difficult (sandy soils, rhizosphere not sticking to roots), which could have caused certain amount of the rhizospheric soil to contaminate the samples. Certain reports [51] showed that the rhizosphere harbored less species than the bulk soil. It is also possible that plants that were common at the Olkusz sites (e.g., Pinus sylvestris) but absent from the Alwernia ones favored specific communities with lower diversity. There are papers showing that plant species together with the soil type determine the shape of the microbial community in the rhizosphere $[52,53]$.

The bacterial communities at the level of phyla were similar in all our samples, in spite of the distance separating the sampling sites and the differences in other parameters such as the plant cover and the contamination. They were generally similar to those found in other soils analyzed by the pyrosequencing-based methods, even though different primer systems were used. Proteobacteria were found to be the dominant phylum both in grassland (e.g., [16-18]) and forest soils [16], just as in the Olkusz and Alwernia samples. Other abundant phyla were Actinobacteria and Acidobacteria followed by Bacteroidetes and Firmicutes. The three first phyla were also present in high numbers in our samples; however, the last one was relatively rare. Thus, the level of phylum does not seem to be adequate for assessing differences in soil bacterial communities. The same, to a lesser extent, applies also to the class level. Lower levels should therefore be used if the effect of heavy metals is to be demonstrated. In our case, both the levels chosen ( 0.03 - roughly species, 0.10 family) allowed the demonstration of $\mathrm{Zn}$ influence on bacterial communities. It seems that the lower the level, the more specific effects can be seen, but on the other hand going below the 0.03 dissimilarity is difficult due to the sequencing noise, therefore constructing the OTUs at the 0.03 level is now the best choice. For large studies, it might be that higher levels would be more appropriate, as the variability at the strain or species level may be too high.

As we were interested in defining the core microbiome of our samples, we decided to use the level of species and families $(0.03$ and 0.10 OTUs, respectively). We chose to assign evenly distributed OTUs with over two reads in each sample to the core microbiome to lower the probability that rare sequences that were present in one or more samples purely by chance (e.g., due to the erroneous reading of a MID sequence) would be taken as shared. Core microbiomes were to date determined for various parts of human body in the Human Microbiome Project (e.g., [46]) and outside of HMP [54]; however, to our knowledge, this is the first attempt to define the core microbiome of soil samples. Our samples' core microbiome appeared to be fairly large and even at the 0.03 level, a single OTU (Otu5214, Sphingomonas) constituted over $0.5 \%$ of total reads number in each sample. At the level of 0.10 dissimilarity, there were six such OTUs, some of them present at the level over $1.71 \%$. In the case of human body core microbiomes, they were impossible to define at low phylogenetic levels and no abundant OTUs (over $0.5 \%$ of reads from each sample) were universally shared [54]. As our samples were diverse in terms of physicochemical properties except for the $\mathrm{Zn}$ contamination, it seems that the core OTUs represent bacteria that are adapted to heavy metals, albeit various ones $(\mathrm{Zn}$ and $\mathrm{Pb}$ in Olkusz samples, while $\mathrm{Zn}$ and $\mathrm{Cr}$ in Alwernia). It would be interesting to see if more geographically distant samples also share so many phylotypes at low phylogenetic level and if the core genes set could be defined. The latter question could be addressed by deep sequencing of metagenomic DNA, assembly, and analysis of genes encoded on the assembled contigs.

In conclusion, our work showed that OTUs constructed at the 0.03 and 0.10 levels allow assessing the influence of heavy metals on both bacterial diversity and community structure. $\mathrm{Zn}$ turned out to be the factor that had the greatest impact on these parameters, other were less important; in particular, no correlation between plant diversity and bacterial diversity was observed. We defined our samples core microbiome comprising Holospora and Sphingomonas (Alphaproteobacteria) as well as KD4-96 (Chloroflexi) and an unclassified member of Acidobacteriaceae at the species (0.03) level and Cytophagaceae, Chitinophagaceae, Acidobacteriaceae, KD4-96, Sphingomonadaceae, and Nitrosomonadaceae at the family level $(0.10)$.

Acknowledgments This work was supported by the Nicolaus Copernicus University (grant no. 2009/312-B to MG) and Polish Ministry of Science and Higher Education (grant no. N N302 094834 to AT, ED-S, and MG, additional support was provided by grants AODP/09/2010/0 and N304 03832/1819 to BW). We are grateful to Dr. Marcin Chodak for helpful discussions and to the anonymous reviewers for their help in improving the manuscript.

Open Access This article is distributed under the terms of the Creative Commons Attribution License which permits any use, distribution, and reproduction in any medium, provided the original author(s) and the source are credited.

\section{References}

1. Baek KH, Yoon BD, Kim BH, Cho DH, Lee IS et al (2007) Monitoring of microbial diversity and activity during bioremediation of crude oil-contaminated soil with different treatments. J Microbiol Biotechnol 17:67-73 
2. Frostegård Å, Tunlid A, Bååth E (1993) Phospholipid fatty acid composition, biomass, and activity of microbial communities from two soil types experimentally exposed to different heavy metals. Appl Environ Microbiol 59:3605-3617

3. Sandåå R-A, Torsvik V, Enger Ø (2001) Influence of long term heavy-metal contamination on microbial communities in soil. Soil Biol Biochem 33:287-295

4. Ellis RJ, Morgan P, Weightman AJ, Fry JC (2003) Cultivation-dependent and -independent approaches for determining bacterial diversity in heavy-metal-contaminated soil. Appl Environ Microbiol 69:3223-3230

5. Lorenz N, Hintemann T, Kramarewa T, Katayama A, Yasuta T et al (2006) Response of microbial activity and microbial community composition in soils to long-term arsenic and cadmium exposure. Soil Biol Biochem 38:1430-1437

6. Müller AK, Westergaard K, Christensen S, Sørensen SJ (2001) The effect of long-term mercury pollution on the soil microbial community. FEMS Microbiol Ecol 36:11-19

7. Gans J, Wolinsky M, Dunbar J (2005) Computational improvements reveal great bacterial diversity and high metal toxicity in soil. Science 309:1387-1390

8. Hugenholtz P, Goebel BM, Pace NR (1998) Impact of cultureindependent studies on the emerging phylogenetic view of bacterial diversity. J Bacteriol 180:4765-4774

9. Handelsman J (2004) Metagenomics: application of genomics to uncultured microorganisms. Microbiol Mol Biol Rev 68:669-685

10. Bakken LR, Olsen RA (1987) The relationship between cell-size and viability of soil bacteria. Microb Ecol 13:103-114

11. Bakken LR (1997) Culturable and nonculturable bacteria in soil. In: van Elsas JD, Trevors JT, Wellington EMH (eds) Modern soil microbiology. Marcel Dekker, New York, pp 47-61

12. Weisburg WG, Barns SM, Pelletier DA, Lane DJ (1991) 16S ribosomal DNA amplification for phylogenetic study. J Bacteriol 173: 697-703

13. Scholtz HC, Al Dahouk S, Tomaso H, Neubauer H, Witte A et al (2008) Genetic diversity and phylogenetic relationships of bacteria belonging to the Ochrobactrum-Brucella group by recA and $16 \mathrm{~S}$ rRNA gene-based comparative sequence analysis. Syst Appl Microbiol 32:1-16

14. Roesch LFW, Fulthorpe RR, Riva A, Casella G, Hadwin AKM et al (2007) Pyrosequencing enumerates and contrasts soil microbial diversity. ISME J 1:283-290

15. Fulthorpe RR, Roesch LFW, Riva A, Triplett EW (2008) Distantly sampled soils carry few species in common. ISME J 2:901-910

16. Nacke H, Thürmer A, Wollher A, Will C, Hodac L et al (2011) Pyrosequencing-based assessment of bacterial community structure along different management types in German forest and grassland soils. PLoS ONE 6:e17000

17. Will C, Thürmer A, Wollherr A, Nacke H, Herold N et al (2010) Horizon-specific bacterial community composition of German grassland soils, as revealed by pyrosequencing-based analysis of $16 \mathrm{~S}$ rRNA genes. Appl Environ Microbiol 76:6751-6759

18. Hur M, Kim Y, Song H-R, Kim JM, Choi YI et al (2011) Effect of genetically modified poplars on soil microbial communities during the phytoremediation of waste mine tailings. Appl Environ Microbiol 77:7611-7619

19. Chodak M, Gołębiewski M, Morawska-Płoskonka J, Kuduk K, Niklińska M (2013) Diversity of microorganisms from forest soils differently polluted with heavy metals. Appl Soil Ecol 64:7-14

20. Sheik CS, Mitchell TW, Rizvi FZ, Rehman Y, Faisal M et al (2012) Exposure of soil microbial communities to chromium and arsenic alters their diversity and structure. PLoS ONE 7(6):e40059. doi:10. 1371/journal.pone.0040059

21. Schloss PD, Westcott SL, Ryabin T, Hall JR, Hartmann M et al (2009) Introducing mothur: open-source, platform-independent, community-supported software for describing and comparing microbial communities. Appl Environ Microbiol 75:7537-7541

22. Dzwonko Z (2007) Guide to phytosociological analysis. Vademecum Geobotanicum. Sorus, Institute of Botany Jagiellonian University, Krakow-Poznan

23. Lindsay WL, Norvell WA (1969) Development of a DTPA micronutrient soil test. Agron Abstr 84

24. Quast C, Pruesse E, Yilmaz P, Gerken J, Schweer T et al (2013) The SILVA ribosomal RNA gene database project: improved data processing and web-based tools. Nucl Acids Res 41:D590-D596

25. Cole JR, Wang Q, Cardenas E, Fish J, Chai B et al (2009) The Ribosomal Database Project: improved alignments and new tools for rRNA analysis. Nucl Acids Res 37:D141-D145

26. Klindworth A, Pruesse E, Schweer T, Peplies J, Quast C et al (2013) Evaluation of general $16 \mathrm{~S}$ ribosomal RNA gene PCR primers for classical and next-generation sequencing-based diversity studies. Nucl Acids Res 41:e1

27. Zhou J, Bruns MA, Tiedje JM (1996) DNA recovery from soils of diverse composition. Appl Environ Microbiol 62:316-322

28. Deja-Sikora E (2012) Search for bacterial cadmium, zinc, lead, copper and chromium resistance genes in metagenome of soils polluted with heavy metals. $\mathrm{PhD}$ thesis, Nicolaus Copernicus University, Torun, Poland

29. Neefs J-M, Van De Peer Y, Hendriks L, De Wachter R (1990) Compilation of small ribosomal subunit RNA sequences. Nucleic Acids Res 18:2237-2317

30. Lane DJ (1991) 16S/23S rRNA sequencing. In: Stackebrandt E, Goodfellow MD (eds) Nucleic acid techniques in bacterial systematics. John Wiley and Sons, New York, pp 115-175

31. R Development Core Team (2011) R: A language and environment for statistical computing. R Foundation for Statistical Computing, Vienna, Austria. ISBN 3-900051-07-0, URL http:// www.R-project.org/

32. Quince C, Lanzen A, Davenport RJ, Turnbaugh PJ (2011) Removing noise from pyrosequenced amplicons. BMC Bionformatics 12:38

33. Edgar RC, Haas BJ, Clemente JC, Quince C, Knight R (2011) UCHIME improves sensitivity and speed of chimera detection. Bioinformatics 27:2194-2200

34. Huse S, Huber J, Morrison H, Sogin M, Welch MD (2007) Accuracy and quality of massively parallel DNA pyrosequencing. Genome Biol 8:R143

35. Chao A (1984) Nonparametric estimation of the number of classes in a community. Scand J Stat 11:265-270

36. Chao A, Lee S-M (1992) Estimating the number of classes via sample coverage. J Am Stat Assoc 87:210-217

37. Bunge J (2011) Estimating the number of species with catchall. Pac Symp Biocomput 2011:121-130

38. Faith DP, Lozupone CA, Nipperess D, Knight R (2009) The cladistic basis for the phylogenetic diversity (PD) measure links evolutionary features to environmental gradient and supports broad applications of microbial ecology's "Phylogenetic Beta Diversity" framework. Int J Mol Sci 10:4723-4741

39. Horn H (1966) Measuring of "overlap" in comparative ecological studies. Am Nat 100:419-424

40. Bray JR, Curtis JT (1957) An ordination of upland forest communities of southern Wisconsin. Ecol Monogr 27:325-349

41. Schloss PD, Handelsman J (2006) Introducing TreeClimber, a test to compare microbial community structure. Appl Environ Microbiol 72: 2379-2384

42. Lozupone CA, Hamady M, Kelley ST, Knight R (2007) Quantitative and qualitative beta diversity measures lead to different insights into factors that structure microbial communities. Appl Environ Microbiol 73:1576-1585

43. Sheneman L, Evans J, Foster JA (2006) Clearcut: a fast implementation of relaxed neighbor joining. Bioinformatics 22:2823-2824 
44. Oksanen J, Blanchet FG, Kindt R, Legendre P, Minchin PR et al (2013) Vegan: Community ecology package. R package version 2.07. http://CRAN.R-project.org/package=vegan

45. Harrell FE et al (2013) Hmisc: Harrell miscellaneous. R package version 3.10-1.1. http://CRAN.R-project.org/package=Hmisc

46. Turnbaugh PJ, Ley RE, Hamady M, Fraser-Liggett CM, Knight R et al (2007) The human microbiome project. Nature 449:804-810

47. Cabała J (2009) Heavy metals in ground soil environment of Olkusz area of $\mathrm{Zn}-\mathrm{Pb}$ ore exploitation. University of Silesia Press, Katowice

48. Berg J, Brandt KK, Al-Soud WA, Holm PE, Hansen LH et al (2012) Selection for Cu-tolerant bacterial communities with altered composition, but unaltered richness, via long-term $\mathrm{Cu}$ exposure. Appl Environ Microbiol 78:7438-7446

49. Chau JF, Bagtzoglou AC, Wilig MR (2011) The effect of soil texture on richness and diversity of bacterial communities. Environ Forensics $12: 333-341$
50. Carson JK, Gonzalez-Quinones V, Murphy DV, Hinz C, Shaw JA et al (2010) Low pore connectivity increases bacterial diversity in soil. Appl Environ Microbiol 76:3936-3942

51. Uroz S, Buee M, Murat C, Frey-Klett P, Martin F (2010) Pyrosequencing reveals a contrasted bacterial diversity between oak rhizosphere and surrounding soil. Environ Microbiol Rep 2: 281-288

52. Marschner P, Yang C-H, Lieberei R, Crowley DE (2001) Soil and plant specific effects on bacterial community composition in the rhizosphere. Soil Biol Biochem 33:1437-1445

53. Ladygina N, Hedlund K (2010) Plant species influence microbial diversity and carbon allocation in the rhizosphere. Soil Biol Biochem 42:162-168

54. Ravel J, Gajer P, Abdo Z, Schneider GM, Koenig SS et al (2011) Vaginal microbiome of reproductive-age women. PNAS 108(S1): $4680-4687$ 